\title{
EDITORIAL POINT OF VIEW
}

\section{Myocardial Perfusion Imaging in East and West: Challenge or Chance?}

\author{
Sang-Geon Cho, $\mathrm{MD}^{1)}$ and Henry Hee-Seung Bom, MD, PhD, FANMB ${ }^{2)}$
}

Received: July 25, 2017/Revised manuscript received: July 26, 2017/Accepted: July 26, 2017

(C) The Japanese Society of Nuclear Cardiology 2017

Ann Nucl Cardiol $2017 ; 3$ (1) : 190-191

\section{See page 186}

$I^{\prime}$ $\mathrm{n}$ this issue of the Annals of Nuclear Cardiology, Kasai elegantly review the trend of myocardial perfusion imaging (MPI) in Japan (1). He showed a trend of decreasing usage of MPI in Japan, by the growing number of percutaneous coronary intervention (PCI), fractional flow reserve (FFR), and computed tomography coronary angiography (CTCA). There is also the same trend of decreasing use of MPI in USA, where the number of US patients with coronary artery disease (CAD) and cardiac procedures is also decreasing. He concluded that the role of stress MPI as a gate keeper for coronary angiography (CAG) and percutaneous coronary intervention (PCI) may be partially replaced by FFR-CT in the near future. It is a timely question to ask why the use of MPI is decreasing both in East and West despite different situations, and what challenges and chances we have.

\section{Challenges of MPI}

Assessment of coronary physiology and ischemic burden becomes an essential procedure before invasive CAG and PCI in patients with stable CAD. MPI has been regarded as a relevant and clinically feasible tool in the initial assessment of patients with stable chest pain. Significant ischemia of more than $10 \%$ left ventricular area is associated with better outcome by PCI than medical treatment (2). A recent study showed that nuclear MPI-based initial approach was associated with significantly better prognosis, as compared to direct referral for invasive coronary angiography (CAG) (3).

Preference of tools to assess coronary physiology was changed by clinical trials introducing FFR and CTCA. The
COURAGE trial showed no prognostic gain of routine PCI for anatomically significant CAD (4), and the FAME trial showed improved prognosis by FFR-guided PCI (5). The PLATFORM trial showed lower rates of unnecessary CAG after CTCA as compared to MPI (6). The PROMISE trial showed less radiation exposure by CTCA than nuclear MPI (7). The SCOT-HEART trial showed improved diagnostic certainty by use of CTCA as the initial diagnostic tool for the evaluation of stable chest pain as compared to MPI (8).

The calculation of the pre-test probability of significant CAD uses out-of-date study results which are based on patients referred for CAG. The actual prevalence of significant CAD was quite lower than expected in patients with high pretest probability (9). The prevalence of significant ischemia on nuclear MPI is also decreasing, resulting in 'too much negative scans' (10). These important changes-less ischemia, less CAD - inevitably lead to the preference for imaging tools with a high negative predictive value such as CTCA. Clinical practices are already being influenced as shown in the UK: the updated NICE 2016 guideline recommends that CT be performed as the modality of choice in patients with typical or atypical angina symptoms regardless of pre-test probability (11).

\section{Chances for multimodality imaging}

It should be noted that the functional studies, which were grouped as one modality entity in recent CTCA trials (6-8) consisted with substantially heterogeneous imaging and nonimaging studies (e.g., exercise electrocardiography). The endpoints used in those trials are advantageous for anatomical studies as they were mainly based on anatomical CAD

doi: 10.17996/anc.17-00043

1) Sang-Geon Cho

Department of Nuclear Medicine, Chonnam National University

Hospital, Gwang-ju, Republic of Korea

2) Henry Hee-Seung Bom

Department of Nuclear Medicine, Chonnam National University

Hwasun Hospital, Jeollanam-do, Republic of Korea

E-mail: hsbom@jnu.ac.kr 
visualized on CAG. It is not yet appropriate to simply let CTCA replace nuclear MPI. Nuclear MPI and CTCA are not competing but complimentary. The two imaging tools can be chosen by more accurately validated pre-test probability. In patients with intermediate-to-high pre-test probability of significant CAD, MPI would be more effective directly deciding the need for PCI. In those with low-to-intermediate pre-test probability, CTCA can be an optimal tool. Nuclear MPI and CTCA represent coronary physiology and anatomy, respectively. Coronary flow physiology can be explained by the anatomical features of epicardial CAD (12-14). The additional information obtained by combined MPI and CTCA can guide treatment. In patients with diffuse atherosclerosis showing decreased coronary flow reserve bypass surgery resulted in better prognosis as compared to PCI (15).

\section{Acknowledgment}

None.

\section{Sources of funding \\ None.}

\section{Conflicts of interest}

None.

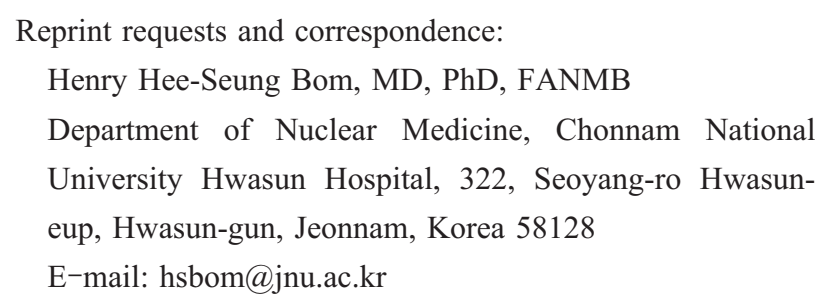

\section{References}

1. Kasai T. Trends and perspectives of stress myocardial perfusion imaging in Japan. Ann Nucl Cardiol 2017; 3: 186-9.

2. Hachamovitch R, Hayes SW, Friedman JD, et al. Comparison of the short-term survival benefit associated with revascularization compared with medical therapy in patients with no prior coronary artery disease undergoing stress myocardial perfusion single photon emission computed tomography. Circulation 2003; 107: 2900-7.

3. Park GM, Kim YH, Yun SC, et al. Anatomic or functional evaluation as an initial test for stable coronary artery disease: a propensity score analysis. J Nucl Med 2016; 57: 1364-9.

4. Boden WE, O'Rourke RA, Teo KK, et al. Optimal medical therapy with or without PCI for stable coronary disease. N Engl J Med 2007; 356: 1503-16.

5. Tonino PA, De Bruyne B, Pijls NH, et al. Fractional flow reserve versus angiography for guiding percutaneous coronary intervention. N Engl J Med 2009; 360: 213-24.

6. Douglas PS, Pontone G, Hlatky MA, et al. Clinical outcomes of fractional flow reserve by computed tomographic angiography-guided diagnostic strategies vs. usual care in patients with suspected coronary artery disease: the prospective longitudinal trial of FFRCT: outcome and resource impacts study. Eur Heart J 2015; 36: 3359-67.

7. Douglas PS, Hoffmann U, Patel MR, et al. Outcomes of anatomical versus functional testing for coronary artery disease. N Engl J Med 2015; 372: 1291-300.

8. SCOT-HEART investigators. CT coronary angiography in patients with suspected angina due to coronary heart disease (SCOT-HEART): an open-label, parallel-group, multicentre trial. Lancet 2015; 385: 2383-91.

9. Khan JM, Harrison R, Schnaar C, et al. Do NICE tables overestimate the prevalence of significant CAD? Br J Cardiol 2014; $21: 75$.

10. Rozanski A, Gransar H, Hayes SW, et al. Temporal trends in the frequency of inducible myocardial ischemia during cardiac stress testing: 1991 to 2009. J Am Coll Cardiol 2013; 61: 1054-65.

11. Moss AJ, Williams MC, Newby DE, et al. The updated NICE guidelines: cardiac CT as the first-line test for coronary artery disease. Curr Cardiovasc Imaging Rep 2017; 10: 15.

12. Greenwood JP, Ripley DP, Berry C, et al. Effect of care guided by cardiovascular magnetic resonance, myocardial perfusion scintigraphy, or NICE guidelines on subsequent unnecessary angiography rates: the CE-MARC 2 randomized clinical trial. JAMA 2016; 316: 1051-60.

13. Dey D, Diaz Zamudio M, Schuhbaeck A, et al. Relationship between quantitative adverse plaque features from coronary computed tomography angiography and downstream impaired myocardial flow reserve by $13 \mathrm{~N}$-ammonia positron emission tomography: a pilot study. Circ Cardiovasc Imaging 2015; 8: e003255.

14. Cho SG, Park KS, Kim J, et al. Coronary flow reserve and relative flow reserve measured by $\mathrm{N}-13$ ammonia PET for characterization of coronary artery disease. Ann Nucl Med 2017; 31: 144-52.

15. Taqueti VR, Hachamovitch R, Murthy VL, et al. Global coronary flow reserve is associated with adverse cardiovascular events independently of luminal angiographic severity and modifies the effect of early revascularization. Circulation 2015; 131: 19-27. 